\title{
Uma abordagem filosófica da pesquisa em educação ambiental*
}

\author{
MARTHA TRISTÃO \\ Universidade Federal do Espírito Santo, \\ Vitória, ES, Brasil
}

\section{APRESENTAÇÃO}

A educação ambiental é compreendida como filosofia de vida e não como uma disciplina obrigatória que se soma às outras disciplinas de um currículo ou a um tema, mas como uma orientação para conhecer e compreender em sua complexidade a natureza e a realidade socioambiental. Este artigo tem a intenção de associar o pensamento filosófico ambiental ou os princípios de uma ecofilosofia à pesquisa narrativa em educação ambiental, observando o seu impacto na ciência, na vida e no desenvolvimento de sociedades sustentáveis. Portanto, a abordagem metodológica que defendemos passa necessariamente por uma investigação filosófica.

Os problemas ambientais, como problemas humanos e complexos, podem nos levar a descobrir a conexão humana com a natureza, o padrão de organização que nos liga num círculo permanente entre a vida e a natureza, em um movimento em rede que sustenta ecologicamente o planeta Terra. Assim, o pensamento ecológico, como um paradigma, tem sentido se a abordagem da natureza envolve valores humanos e não se reduz ao aspecto científico apenas. Tal entendimento reconhece a existência de uma razão sensível como parte da natureza humana, suas consequências sociais e impactos ambientais. Nesse sentido, concordando com Maffesoli (2005), reconhecemos o sensível e as implicações de seus efeitos como parte da natureza humana.

* Este artigo foi escrito durante estágio da autora de seis meses para a realização de pesquisa de pós-doutorado na Faculty of Education, University of Regina, Canadá. 
É pertinente para este ensaio relembrar o que o filósofo Félix Guatarri (1990) afirmou há alguns anos em seu livro As três ecologias, quando discorreu sobre uma ecosofia em que três dimensões ecológicas foram abordadas e intrinsecamente inter-relacionadas: meio ambiente, relações sociais e subjetividade humana.

A questão ambiental é um problema social e não existiria sem a produção da subjetividade que implica a formação dos sujeitos ou de componentes de subjetivaça o, ${ }^{1}$ como sugere Guatarri (1990). A educação ambiental conduz um movimento identitário que potencializa a relação com o $\operatorname{lugar}^{2}$ habitado e que problematiza o sentido de estar/habitar/morar no planeta.

No campo da pesquisa qualitativa, são os princípios filosóficos e epistemológicos que sustentam as concepções metodológicas da pesquisa em educação ambiental, como sugere Hart (2005). Um dos pressupostos é o de que sujeito e objeto são indissociáveis. Tentamos transgredir a ideia de que é necessário o distanciamento ou a neutralidade tão propalada pela ciência clássica para garantir a confiabilidade da pesquisa.

Assim, defendemos que a pesquisa em educação ambiental envolve as controvérsias da pesquisa educacional em geral. Então, carecemos de aprofundar o pensamento: qual é a ancoragem, se é que ela existe, que envolve as relações entre realidade e objetividade, realidade e subjetividade, teoria e prática, conhecimento e verdade, linguagem e meio ambiente e as ações humanas (crenças, culturas, valores e potências) que influenciam a descrição do fenômeno?

Aqui estamos tentando trazer como pano de fundo deste debate a necessidade da investigação filosófica para pensar/fazer a pesquisa em educação ambiental. Entender a educação, a formação ambiental e as sociedades requer muitas maneiras diferentes de investigação, abordagens e metodologias para a compreensão do complexo modo de tradução dos significados das práticas socioculturais articuladas com a experiência pessoal.

Dessa forma, iniciamos neste estudo uma cartografia, no sentido metafórico do termo, dos limites e aproximações, ideias e conceitos de autores preocupados com a criação de espaços de convivência e identificações sociológicas e ecológicas: individuais, coletivas e comunitárias (Maffesoli, Maturana, Augé), com as práticas cotidianas de sujeitos praticantes (Certeau) e que compreendem as narrativas como construções culturais (Hart,Bruner) e produções de sentidos nas pesquisas em educação ambiental.

1 Passa por reexaminar a relação entre o indivíduo e a subjetividade. Para Guatarri (1990), o indivíduo se encontra em uma posição terminal no que se refere a grupos humanos, conjuntos socioeconômicos, tecnologias etc. Esses componentes de subjetivação não passam necessariamente pelo indivíduo, a interioridade se instaura no cruzamento de dimensões que são relativamente independentes e às vezes discordantes.

2 Para Certeau (1994), um lugar é organizado por uma série de procedimentos que ele chama de estratégias. As estratégias organizam, determinam um lugar que sofre influências de exterioridade formada por alvos e ameaças. Por meio da escrita que associamos a uma forma de produção narrativa, os sujeitos tentam organizar as sociedades fundadas na estabilidade do texto. 
Precisamos então produzir um enredo para compreender a ideia de natureza, de ciência e de pesquisa, que toma diferente sentido segundo a época e as sociedades humanas. As racionalizações científicas estão condicionadas às diversas noções e usos da natureza que suscitam práticas narrativas que refletem nossas relações com o mundo e se inserem no movimento de busca ontológica e epistemológica do campo de pesquisa em educação ambiental.

Como o cerne da dimensão ambiental está na formação dos matizes de valores, atitudes e comportamentos pelos sujeitos/sociedade, alguns questionamentos que integram há bastante tempo as nossas preocupações nas produções acadêmico-científicas nos servem de bússola, como: será possível revertermos os fundamentos da ciência moderna com pressupostos hegemônicos de dominação e mercantilização da natureza, de economização do mundo e de valores consumistas de excesso e de desperdício?

\section{A PRODUÇÃO DE VALORES E DE FILOSOFIAS EM ESPAÇO DE CONVIVÊNCIA SOCIOEDUCATIVO-AMBIENTAL}

Diferentes abordagens da educação ambiental originam uma gama de ideologias ambientais, mas uma ideologia ambiental não pode ser compreendida exceto dentro de ideias e de valores do espectro de crenças e, diríamos, de culturas e de paradigmas sociais (Hart, 2005). O fato é que, segundo Hart, ideologias educacionais, como a ideologia ambiental, são relatadas por ideologias políticas dentro de visões de mundo que vêm de visões particulares da realidade e provêm de bases organizadas pelas comunidades científicas. Podemos, dentro de uma contradição constante, tentar entender como o paradigma social dominante influencia a visão ambiental de mundo.

A concepção de visão de mundo não pressupõe uma ação meramente racional; uma visão de mundo implica uma forma de teorização sobre o mundo, uma imanência entre as palavras e as coisas (Veiga-Neto, 2007). E as narrativas são compreendidas como acontecimentos, eventos, ações, experiências que expressam o enredo vivido dos saberes produzidos e subjetivações articuladas com base em interações com o meio ambiente por meio de expressões socioculturais.

A relação de si consigo mesmo, como diria Foucault, como cada um se vê a si mesmo, só pode ser colocada em movimento como um dos elementos de uma ontologia que engloba os dois eixos - do ser poder e do ser saber - de modo inter-relacionado e simultâneo. No espaço projetado dessas relações, o sujeito é um produto dos saberes, dos poderes e da ética (idem). Como numa relação complexa, esses eixos são interdependentes, complementares e contraditórios.

Maturana (1997) não concebe a ideia de sujeito absoluto e nem da linguagem privada. Para o autor, objetos cognoscíveis e sujeitos cognoscentes são configurados no viver de um observador que surge quando nós, humanos, de algum modo, realizamos distinções na linguagem, ou seja, não há uma realidade dada a ser interpretada pelo sujeito. Ainda para Maturana (1997, p. 24), “[...] todo argumento é universal 
no seu domínio de validade: todo argumento especifica o seu domínio de validade e, portanto, especifica também o universo no qual é válido".

Então, a realidade deixa de ser uma construção desinteressada e um dado externo a ser acessado por uma razão que irá iluminar o caminho da investigação. Segundo Maturana (1997), essa ideia de realidade objetiva se torna referência de algo que se supõe universal e independente do que fazemos. Se considerarmos que a história da ideia de natureza foi construída em cima de muitas interpretações narrativas, com uma ideia que foi ao longo do tempo promovendo uma racionalidade funcional, com um utilitarismo extremo entre as relações humanas colonizadoras e a natureza, podemos compreender os impactos ambientais de hoje. Ao mesmo tempo, observamos as consequências sociais e éticas dessa ontologia da realidade na produção da ciência ocidental impregnada pela racionalização exacerbada de argumentos que estigmatizam o senso comum e desqualificam o equilibrio orgânico, que por sua vez impregna o pensamento de sociedades com outros modos de vida e maneiras de se relacionar com a natureza.

Como bem argumenta Maffesoli (2005, p. 30),

Enquanto que para o racionalismo "o terceiro é excluído", o conhecimento tradicional, a sabedoria popular, ou simplesmente a experiência empírica nos ensinam que "o terceiro é sempre dado", que é impossível fazer repousar todas as coisas sobre uma discriminação estrita, e que, em seus diversos aspectos, a vida é um movimento perpétuo onde se exprime a união dos contrários.

Essa lógica dos contrários que mantém juntos os aspectos da existência compreende uma diversidade filosófica necessária para fundamentar a educação ambiental, confia e respeita a variedade de aproximações que ajudam a entender as interações e intenções da complexidade humana. Nesse caso, mais uma vez percebemos que o racionalismo clássico não foi sensível à força de seu contrário, porque não soube integrá-lo às formas humanas do que se convencionou chamar de irracionalismo. A visão racionalista de mundo e da vida tem como base processos racionalizadores e ideologias, como a noção de recursos humanos ou de recursos naturais e de promoção da homogeneização que despreza o diferente e o taxa como inferior, de populações primitivas, atrasadas, subdesenvolvidas.

De fato, a educação ambiental, como uma antidisciplina, não pode se fechar a uma razão única, pois ela se sustenta em uma racionalidade mais aberta. Como sugere Morin (2008), em sua ciência com consciência, essa racionalidade aberta pode ser considerada, em termos filosóficos, uma audácia de pensamento, com uma racionalidade mais ampla, flexível, inventiva e sobretudo carregada de um sentimento de que é aleatória, precária e submissa ao acontecimento (Maffesoli, 2005) entre as relações sociedade-meio ambiente, cultura-natureza.

O que observamos hoje em impactos ambientais do processo de globalização hegemônica, que muitos interpretam como uma expressão do irracionalismo, pode ser considerado, em nosso entendimento, a mais profunda expressão do racionalismo, que encara a natureza como fonte de exploração e leva aos limites a supremacia 
da razão científica moderna. Essa racionalidade fechada é insensível à fragilidade do equilíbrio ecossistêmico - que é imprescindível à sustentabilidade ecológica do planeta Terra -, aos problemas socioambientais globais provenientes de uma intervenção incongruente com o meio ambiente, como é o caso dos efeitos produzidos pela emissão de gases de efeito estufa, consequência das alterações climáticas a que estamos assistindo, já confirmada pelo expertise. ${ }^{3}$

Até o momento, na transição de reconhecer e aceitar diversos modos de conhecer e ver o mundo em nossas pesquisas, há o risco de falharmos ao não reconhecer o valor de outras posições filosóficas que se fundamentam em uma racionalidade mais ampla, por conta da nossa limitação ou porque essas posições são entendidas de forma parcial e incompleta e/ou não são articuladas pelos próprios pesquisadores. A nossa opção, em termos filosóficos, e a prática da pesquisa têm uma relação política que às vezes não percebemos porque desarticulamos a ciência da política e das relações de poder.

Esse debate pode trazer um profundo impacto ao potencial emancipatório da educação ambiental que não faz pesquisa desinteressada, mas encarna o movimento ético constante entre a pesquisa e o universo pesquisado, num desejo de superação da lógica perversa do racionalismo moderno que promove um desenvolvimento a qualquer custo, degrada e destrói com força brutal a naturezacultura.

Nesse caso, a pesquisa em educação ambiental tem uma relação profunda entre fato e valor, tornando o/a pesquisador/a eticamente responsável no enfrentamento das relações meio ambiente e desenvolvimento. Como Hart (2003b), perguntamos o que nossos leitores e leitoras da pesquisa em educação ambiental pensam sobre problematizações que, às vezes, tomam como garantia relações que aumentam o conhecimento sobre questões de ecologia, meio ambiente e desenvolvimento, orientando para um aumento de efeito ou de responsabilidade pelo espaço ambiental que gostaríamos de ter.

Não temos ainda explicações para essa e outras questões no movimento desse campo de pesquisa, mas concordamos com Hart (2005), que diz que a prática da pesquisa não pode ser entendida exceto dentro de sistemas de pensamento que fazem deles inteligíveis ou compreensíveis. Ou seja, precisamos tornar compreensíveis e disponíveis nossas produções científicas e textos acadêmicos.

E daí, talvez, na genealogia do poder em Foucault (apud Veiga-Neto, 2007, p. 59), possamos pensar, compreender melhor esse gargalo da pesquisa em educação ambiental,

3 Segundo relatório divulgado em 2007 pelo Intergovernmental Panel on Climate Change (IPCC) (Painel Intergovernamental sobre Mudanças Climáticas), estabelecido pelo Programa das Nacões Unidas para o Meio Ambiente (PNUMA), o aquecimento do sistema climático é inequívoco e tanto a emissão passada como a futura de dióxido de carbono antropogênico continuarão a contribuir para mudanças ambientais globais. 
Não tanto contra os conteúdos, os métodos e os conceitos de uma ciência, mas de uma insurreição sobretudo e acima de tudo contra os efeitos centralizadores de poder que são vinculados à instituição e ao funcionamento de um discurso científico organizado no interior de uma sociedade como a nossa. E se essa institucionalização do discurso científico toma corpo numa universidade ou, de um modo geral, num aparelho pedagogico, [...]? no fundo pouco importa. É exatamente contra os efeitos de poder próprios de um discurso considerado científico que a genealogia deve travar o combate.

Não é uma surpresa que a pesquisa em educação ambiental tenha incluído uma crítica ao modo da ciência dominante na investigação em educação (Hart, 2005). No paradigma dominante da ciência moderna, os fatos precisam ser medidos ou pesados. Mas as relações sociais e humanas com o meio ambiente e uma perspectiva socioecológica da educação e do desenvolvimento não podem ser medidas nem pesadas, podem ser mapeadas ou cartografadas. Então, assumimos uma mudança, quando se trata da pesquisa em educação ambiental, em vez de medir, cartografar e narrar. A intenção é contribuir para um campo de pesquisa que vá além de um método e de uma metodologia de dimensões discursivas/políticas/filosóficas que orientam a investigação. ${ }^{4}$

De acordo com Maffesoli (2005), a ciência contemporânea introduz um mundo em que a verdade é tributária de valor, ou melhor, um mundo em que há uma interação permanente entre a verdade e os valores socialmente vividos. Assim,

[...] não há mais uma verdade única, geral, aplicável em qualquer tempo e lugar, mas, ao contrário, uma multiplicidade de valores que se relativizam uns aos outros, se completam, se nuançam, se combatem, e valem menos por si mesmos que por todas as situações, fenômenos, experiências que supostamente exprimem. (idem, p. 56)

Os valores são inerentes aos "modos de vida", e os modos de vida em sua complexa rede de interações cotidianas produzem a cultura. Esses valores, como alerta Bruner (1997), não são produtos isolados, são consequências de nossas relações e experiências cotidianas com uma comunidade cultural. Nesse sentido, vale pensar

4 Uma análise de trabalhos de grupos de pesquisas vinculados ao Grupo de Trabalho Educação Ambiental (GT22) da Associação Nacional de Pós-Graduação e Pesquisa em Educação (ANPEd) revelou alguns traços identitários que configuram certa particularidade dos grupos de pesquisa em educação ambiental. Essa mesma análise fundamentou suas propostas de ação e de pesquisa em vinculações iniciais com projetos, envolvendo ações educativas que buscam transformar realidades. Chama a atenção o fato de que, na maioria dos textos elaborados pelos grupos, a motivação para a estruturação dos grupos/núcleos de pesquisa nasce com uma experiência de ação, inicialmente não voltada para a produção acadêmica de conhecimento. Em outras palavras, pode-se imprimir um sentido político às ações, inclusive quando as referências são as ações de pesquisa, nos textos encaminhados pelos grupos (Tristão; Carvalho, 2009). 
sua produção de sentidos nas escolas, pois são os significados culturais que guiam nossos atos individuais. Sem querer, todavia, aprofundar o currículo, um campo tão vasto e repleto de discussão, mas que o tempo todo tangencia a educação ambiental, questionamos: como o currículo pode se tornar com enfoque mais sustentável?

O currículo emerge como uma história mais aberta, perceptor de uma organicidade sincronizada em que natureza e cultura estão em interação, guiado por uma abordagem integrativa e ecológica, podendo abarcar escolhas significativas dos sujeitos aprendentes em uma reflexão sobre o lugar, a tradição, a cultura. As linguagens são carregadas de significados e as palavras têm histórias e preconceitos, como é o caso do sentido atribuído à natureza, à cultura e à tradição, bem como as marcas deixadas pela e por meio da tradição no caso. As comunidades locais, com seus saberes sustentáveis, possuem suas culturas cotidianas, comuns, corriqueiras e tradicionais, mas também participam da cultura global.

Como argumenta Hart (2003a), embora as diretrizes curriculares frequentemente coloquem o lugar da educação ambiental nas propostas educativas das diversas províncias do Canadá, ${ }^{5}$ em relação às disciplinas regulares, ainda persiste uma marginalização curricular do meio ambiente educativo relatado. Em outras palavras, o autor pergunta se os problemas e as questões ambientais justificam os currículos escolares. E aqui seria interessante pensar a educação ambiental como um "não lugar", como argumenta Augé (2004) ao tentar discorrer sobre seu conceito de lugar antropológico ${ }^{6}$ sem opor "lugares" aos "espaços". Também é possível fazer uma alusão à educação ambiental como o espaço que ocupa no currículo vivido, como animação dos lugares ou, como pensa Certeau (1994), de um espaço que ocupa como lugar praticado, como um currículo em ação.

Entendendo o currículo como prática discursiva em ação, podemos dizer que o currículo praticado ou realizado - dentro e fora das escolas - produz narrativas pelas práticas sociais e cotidianas vividas, embora os sujeitos da ação educativa não façam nenhuma distinção entre o que está fora e o que está dentro do meio escolar. Esses acontecimentos diários que tecem redes de saberes e fazeres estão em constante tensão com as práticas de poder.

No Brasil,já existe uma proposta de currículo prescrito em nível nacional, como é o caso dos Parâmetros Curriculares Nacionais, que tratam a educação ambiental como um tema transversal. Pensamos meio ambiente como parte essencial da vida, da

5 A Constituição no Canadá não prevê um currículo ou um programa com diretrizes nacionais. Cada província/território elabora seu currículo, guia e inclui a educação ambiental da forma mais propícia, mas ainda prevalece uma ênfase nas disciplinas ciências e geografia, que têm o relato ambiental em seus principais objetivos. No tema ciências, tecnologia e sociedade, o meio ambiente está incluído.

6 Um lugar pode ser definido como identitário, relacional e histórico. Um espaço que não se pode definir como identitário, nem como relacional, nem como histórico, definirá o que Augé (2004) chama de "não lugar". Os "não lugares" seriam espaços que não são lugares antropológicos. Mas, segundo o autor, nem um nem outro existe sob uma forma pura, o lugar não é totalmente apagado e o e "não lugar" nunca se realiza totalmente. 
cultura e da natureza, que não pode ser considerado um tema, mas parte integrante de qualquer projeto educativo. Reconhecemos, com nossas idas e vindas às escolas, que a educação ambiental desenvolve um potencial de paixão entre os professores/as, diferente de certas formas de educação, como a matemática ou ciências, talvez porque sua proposta seja menos dogmática e aberta ao lá fora de qualquer fronteira, seja física, seja epistemológica. O que é também reconhecido por Hart (2003a) em relação aos professores canadenses, fato que ele justifica como fundamentos próprios da educação ambiental, ligados às formas de ação e da vida comunitária.

Como já temos argumentado sobre o encantamento provocado pela educação ambiental, pela sua conectividade com uma razão sensível em que a natureza é encarnada na produção de subjetividades, a ideia que perpassa entre os professores/as educadores/as ambientais é: sei da sua importância, reconheço, mas não sei muito bem como fazer. Em contrapartida, percebemos a existência dos mais audaciosos, que não têm medo de ousar e que intuitivamente criam oportunidades e experiências fantásticas em seus espaços vivenciais de aprendizagemensino. Esses espaços vivenciais são abertos e não dogmáticos, o que, de acordo com Maturana (1997), garante um sistema de conversações que permite perturbações mútuas disparadoras de processos internos.

Conforme Hart (2003a), essa reivindicação epistemológica da educacão ambiental não implica, contudo, que esse ponto de vista do pensamento do professor/a, radicado no espiritual, no processo moral ou psicológico, não deva ser discutido ou debatido, ou seja, não é menos importante que o processo cognitivo da aprendizagem. De fato, esse é justamente o debate que deveria caracterizar o campo da educação ambiental. É o que chamamos de uma racionalidade aberta, com um ambiente que favoreça a autoria, a autorreflexão, com práticas transformadoras que suscitam autonarrativas, pois, conforme Maturana (1998), narrar a vida é narrar-se, o que leva a uma maior complexificação, no sentido de maior autonomia e controle sobre nossas vidas. Entendendo de onde viemos poderemos entender para onde vamos.

Entretanto, tanto no Brasil como no Canadá, percebemos que as ações de sala de aula são baseadas em iniciativas de professores mais que em propostas do currículo-base, que os professores/as estão mais perto de suas teorias, do seu conhecimento profissional - para o qual, reconhecimento moral, afetivo e estético, tanto quanto o cognitivo, é forma de conhecimento (Hart, 2003a).

Nós temos, ao mesmo tempo, nos frustrado e nos encorajado com nossas descobertas, argumenta Hart (2003a). No caso brasileiro, muitas de nossas pesquisas não são incorporadas nas políticas, há um distanciamento entre a pesquisa científica e o campo técnico e político. O que começa a ocorrer no campo da pesquisa em educação ambiental, tanto no Brasil como no Canadá, são tentativas de articular as pesquisas às bases filosóficas, ou seja, questionar como os pensamentos e como as pesquisas impactam nosso pensamento e as práticas do nosso campo de trabalho. Qual o impacto da pesquisa em educação ambiental na produção de sociedades sustentáveis? O que é negligenciado e o que é privilegiado nas pesquisas?

$\mathrm{O}$ velho ditado de que a realidade social é negociada, atravessada por eventos socioculturais e históricos, tem nos conduzido a pensar sobre a possibilidade de 
criação de significados e de condições de transformação das comunidades somente com o desafio delas mesmas. Isso com a sensibilidade pós-moderna de suspeitar em sempre acertar, como a narrativas mestras do paradigma dominante da ciência moderna nos impôs.

\section{NARRATIVAS COMO PRODUÇÕES CULTURAIS DAS PESQUISAS EM EDUCAÇÃO AMBIENTAL}

O domínio de uma ou outra abordagem metodológica não nos dá prioridade sobre o que conta como conhecimento ou realidade. Pesquisadores com diferentes pressupostos adotam diferentes métodos (com diferentes modos de compreensão entre métodos e metodologia). Entretanto, a percepção da abordagem metodológica é menos explícita, ou menos necessária, quando o paradigma positivista domina a pesquisa educacional, porque o que mais importa são os métodos. Chamamos a atenção para a necessidade de analisar as controvérsias não somente dentro das comunidades da pesquisa educacional, mas também nas ciências sociais, que têm revelado, fundamentalmente, diferentes modos de percepção de metodologias adotados nas pesquisas qualitativas.

Não cabe aqui analisar essa questão, mas trazemos, como desafio, o lugar da investigação narrativa mesclando com a cartografia socioecológica do espaço como possibilidade de pesquisa em educação ambiental, com a convicção de que outras interpretações ou articulações são possíveis. Trata-se de um texto aberto como um convite aos pesquisadores da área e a outros interessados no tema.

Muitos pesquisadores em educação ambiental estão estabelecendo pontes filosóficas em suas abordagens na investigação educacional, baseadas em sistemas de pensamento, preocupação ecológica, feminismo, pós-modernismo e outras áreas (Hart, 2003b). Essa é uma articulação parcial das associações dentro do desenvolvimento da pesquisa qualitativa, mas particularmente da abordagem criticamente interpretativa e reflexiva. Essa forma de pensamento não é suficiente, a menos que se enfatize a tarefa de aproximações com abordagens práticas dentro de um desenvolvimento refinado de uma variedade de abordagens metodológicas de nossas investigações, de nossos pensamentos e práticas.

A proposta da pesquisa narrativa em educação ambiental tem o poder de revelar as histórias da vida social e transformá-las com os praticantes do processo ao se verem coautores de suas invenções cotidianas. Histórias pessoais articuladas com a vida coletiva e comunitária são ricas em contextos ambientais, históricos e em linguagens, emoções, sentimentos, tradições e ações dos praticantes. Inclusive porque propiciam uma cartografia de práticas sem discurso e nos permitem instaurar uma narrativa sobre essas práticas (Certeau, 1994), numa espacialização em que predomina um determinado discurso. Essa aproximação da análise científica com as práticas cotidianas possibilita compreender os usos que os meios populares fazem das culturas difundidas e impostas ou dos monopólios interpretativos. 
Essa visão do conhecimento narrativo encampa a ideia de que os sujeitos praticantes são parte dos múltiplos conhecimentos das comunidades locais, costumes, lugares onde as pessoas narram suas histórias e experiências. Como sugere Hart (2003a), negociam o que significam e autorizam suas e outras interpretações de situações como relatos legítimos. Narrativa como história não significa um caso de ficção, mas a descrição da experiência vivida em seu lugar de convivência socioambiental. O tema-problema dessas histórias é a ação humana no meio ambiente circunscrito. Para Certeau (1994, p. 166), "[...] a prática discursiva da história é ao mesmo tempo a sua arte e o seu discurso".

Ainda de acordo com Certeau (1994), os relatos caminham à frente das práticas sociais e vão abrindo caminhos numa dinâmica circular, ou seja, os discursos produzidos derivam desses relatos que associamos às produções narrativas; e esses discursos se tornam efetivos quando narrados. Na compreensão de Foucault, em seu aparato disciplinar, as narrativas têm um caráter estratégico (organizam o discurso) ou tático (interferem nas estruturas de poder) (apud Josgrilberg, 2005). Para Certeau (1994), os relatos produzem efeitos que incessantemente transformam os lugares em espaços e os espaços em lugares.

Para muitos de nós, essas histórias capturam mais do que fórmulas matemáticas integrantes das pesquisas quantitativas, porque trazem a riqueza e a complexidade das experiências dos praticantes em suas relações ecológicas com o meio ambiente. A história a que nos referimos, para fazer uma distinção de seu sentido em português, foi escrita durante muito tempo como estória, para diferenciá-la da disciplina, da historiografia, e para imprimir um atributo nada formal ao enredo da vida e das relações sociais que tecemos em nossas ações e redes ambientais cotidianas.

Então, o enredo educativo-ambiental a que nos remetemos não parte necessariamente do historiador/a; é extraoficial e parte de narradores praticantes das redes ambientais cotidianas que frequentemente usam o emocional, o simbólico, a lenda e o mito e se baseiam em valores emocionais. Como diz Maturana (1998), todo sistema racional tem um fundamento emocional. Para alguns pesquisadores, com essa abordagem de pesquisa é possível compreender o contexto político das histórias, suas relações de poder, de gênero e as diferenças das realidades comunitárias.

Para além do monoculturalismo - que é sempre uma ideia de força, de uma cultura de guerra em sentido metafórico, contrário à ideia ecológica de mundo, porque anula a diversidade de pensamentos e de ações -, a produção de narrativas envolve o espaço existencial, ou seja, o lugar de uma experiência com o mundo, do sujeito situado em sua relação com o meio ambiente, em outras palavras, da relação entre a natureza como necessidade e o desenvolvimento societal (Maffesoli, 2001).

Nesse sentido, compreender os saberes tradicionais como repertórios de significado da origem, do lugar próprio, longe de ser uma concepção doutrinária de estilos de vida e de cultura, reafirma o lugar da potência em ação, de lugares antropológicos que ainda mantêm um pouco da história, da identidade e da relação social. Com isso, não estamos propondo uma essencialização da cultura, mas a possibilidade de 
observar a tensão entre tradição e modernidade e de um acoplamento da cultura com a natureza, mediado por processos tecnológicos, sociais e políticos (Tristão, 2010).

Para entender o que acontece, como pesquisadora/produtora de narrativas em dado contexto sociocultural, consideramos eventos ou microeventos conectados às redes de significados. Ao assumirmos a vida como redes, consideramos a existência de suas inter-relações, antagonismos, sincronismos e dependências na dinâmica do sentido narrativo. Há uma história, em outras palavras, uma personificação e padronização sequencial de eventos em volta da figura de significados para uma cultura local e particular que emerge da nossa condição histórica (Bruner, 1997) sem determinismos, mas pelas interações recorrentes com o meio ambiente. Para Maturana (1998), o organismo e o meio se transformam de maneira congruente e a história é um texto que traduz, guia e, narrativamente, produz um enredo das redes de relações cotidianas. Os componentes da história são, implícita e explicitamente, significativos para a configuração da realidade pesquisada.

As histórias tornam-se uma maneira de capturar a complexidade, a especificidade e as interconexões do fenômeno com o qual lidamos. De acordo com Bruner (1997, p. 52), a narrativa adquire sua forma nos resíduos sedimentários dos tradicionais modos de contar, da nossa antiga herança de contar histórias. Mas histórias não se reduzem à lógica tradicional e clássica, porque são dependentes do local; assim sendo, parecem resistir às explanações das leis da ciência clássica - paradigma científico requer consistência e não contradição - e, por sua vez, a história está cheia de ambiguidades e contradições. ${ }^{7}$ Portanto, a abordagem metodológica da educação ambiental não se pode prender às amarras de um caminho determinado, estreito e inflexível. Com isso, não estamos defendendo que não devemos traçar caminhos ou ter pressupostos em nossas pesquisas; nosso argumento é o de acatar o imprevisível em sua trajetória.

De acordo com Bruner (1997), narrativas são explicações das interações humanas no contexto da ação. As histórias que enredam as narrativas, então, têm uma multiplicidade de significados. É como se fossem a paisagem com a qual vivemos e interagimos com o meio ambiente dentro do qual o nosso trabalho, como professoras e pesquisadoras, ganha sentido.

As histórias que vivemos não são permanentes invenções privadas. Nos processos de subjetivação, nós as produzimos com base em informações provenientes da experiência coletiva e das histórias inventadas ou de expectativas preconcebidas de

7 Como exemplo, a própria educação ambiental vem historicamente produzindo uma narrativa ambígua, contraditória, na oscilação entre o novo e o velho, o presente e o passado. Nesse sentido, sem saber, já concordávamos com essa perspectiva de se pensar como Hart (2003a), a educação ambiental é um diverso e pós-moderno campo que resiste a uma definição precisa, em que os contrários convivem sem se excluírem. A racionalidade científica valoriza o tempo cronológico, o tempo contado, o novo, o rápido, o presente, e não o tempo vivido, a tradição, a cultura e a história acumulada pela humanidade. A educação ambiental ocorre no entrelaçamento entre os tempos, no espaço/tempo entre os contextos de aprendizagem e o tempo vivido (Tristão, 2004). 
modos de interpretação apoiados em nossa cultura ordinária. As histórias narradas são como o centro de tradução desse processo. Para compreender o pensamento, então, é necessário encontrar a história em que o modelo individual se estrutura ou que a teoria dos eventos cria na relação de congruência com o meio ambiente. Além disso, o vínculo das narrativas com a autobiografia pode ser considerado para a compreensão dos saberes e fazeres cotidianos, já que ela é pessoal e social ao mesmo tempo.

Nós não somos capazes de representar as histórias dos sujeitos praticantes sem a existência do conhecimento cultural de suas comunidades. A ênfase dada à narrativa não é magnificente, pois reconhecemos que nos movemos além do mero relato. Com efeito, as narrativas de análise abrem brechas para explorar/compreender o que está subtendido na articulação do poder com a potência e o que ensinoaprendo sobre e por intermédio do meio ambiente.

Será que podemos pensar em margens, fronteiras ou centros de nossos mapas mentais ou simbólicos? Histórias expressam saberes e fazeres que descrevem experiências nas quais ações e acontecimentos têm efeitos sustentáveis ou não nas ações ambientais. Mas não defendemos qualquer maniqueísmo interpretativo, e sim apenas a potência da pesquisa narrativa em um conhecimento carregado de histórias que difere do que vem sendo promovido pelo tradicional conhecimento ocidental (Polkinghorne, 1995). A capacidade de entender histórias vem da correlação entre o desdobramento da história, da característica temporal da experiência humana e do entendimento prévio da ação humana (idem).

As fontes das histórias variam, incluindo documentos escritos, jornais, autobiografia, biografia, história oral, entrevistas, imagens fotográficas e filmagens, que são importantes instrumentos porque permitem a visualização e o retorno às ações vividas tanto na pesquisa como nos processos de formação. Nas pesquisas qualitativas da educação ambiental, as entrevistas parecem ser a fonte mais comum.

O que acontece em nome da educação ambiental? Será que estamos prontos para aceitar e comprender as próprias descrições que fazemos e usamos na educação ambiental?

\section{ANOTAÇÕES FINAIS}

As bases ontológicas e epistemológicas que guiam nossos pressupostos metodológicos e informam nossos métodos e ações podem potencializar e enriquecer o campo da educação ambiental de modo geral. Para tanto, é preciso estabelecer um movimento congruente de metodologias de pesquisa com epistemologias e ontologias, questionar a natureza e os usos da interpretação que fazemos, tendo a filosofia como aporte das tentativas paradigmáticas da investigação.

Ouvir descrições de histórias sobre episódios dos movimentos e experiências da vida das pessoas e sobre o meio ambiente como uma realidade vital nos toca de tal modo que evoca emoções, como simpatia, raiva ou tristeza. As narrativas de análise se movem dos acontecimentos para a produção de histórias, e as histórias sem linearidade imprimem um enredo à vida socioambiental e comunitária. $\mathrm{O}$ 
desafio que temos, segundo Hart (2003a), é aprender sobre o espaço interpretativo dentro do qual as histórias podem se tornar um componente importante da pedagogia ambiental.

$\mathrm{Na}$ pesquisa narrativa, os eventos e acontecimentos são dados e o resultado da análise é a produção da história, ou melhor, histórias são produzidas como resultados da pesquisa em educação ambiental. E aqui não estamos nos referindo a uma história marcada por uma temporalidade, ou mais que isso, contextualizada em um lugar próprio, de origem. Essa história pode ser fragmentos narrados, pedaços de informações e experiências que contribuem para a construção da história. Quanto mais temos experiências disponíveis, mais potencializamos experiências de práticas sustentáveis. Estamos nos reportando a uma história como um tipo especial de narrativa, com uma sequência de eventos e de acontecimentos protagonizados pelos sujeitos praticantes da ação social. Assim, as histórias passam a existir independentemente da forma particular de expressão.

Então, a genealogia, em Foucault (apud Veiga-Neto, 2007, p. 60), abre brechas para a relação entre realidade e narrativa ao discorrer sobre o conhecimento científico:

Não se propõe a fazer uma outra interpretação, mas, sim, uma descrição da história das muitas interpretações que nos são contadas e que nos têm sido impostas. Com isso, ela consegue desnaturalizar, desessencializar enunciados que são repetidos como se tivessem sido descobertas e não invenções.

As pessoas produzem sentidos de suas experiências de vida narrando-as, e é assim que podemos, principalmente para aqueles e aquelas que vivem nas margens de uma cartografia dominante do espaço sociocultural, tirar esses sentidos do anonimato.

\section{REFERÊNCIAS}

AugÉ, Marc. Não lugares: introdução a uma antropologia da supermodernidade. 4. ed. São Paulo: Papirus, 2004.

Bruner, Jerome. Actos de significado. Lisboa: Edições 70, 1997.

Certeau, Michel. A invenção do cotidiano: artes de fazer. 3. ed. Petrópolis: Vozes, 1994.

Deleuze, Gilles; Guatarri, Félix. Mil platôs: capitalismo e esquizofrenia. 2. ed. Rio de Janeiro: Editora 34, 1996. $1 \mathrm{v}$.

Guattari, Félix. As três ecologias. Tradução de Maria Cristina F. Bittencourt. Campinas: Papirus, 1990.

Hart, Paul. Teachers' thinking in environmental education: consciousness and responsibility. New York: Peter Lang, 2003a.

. Environmental educators: a conversation with Paul Hart.Journal of Environmental Education, Philadelphia: Taylor \& Francis Group, v. 34, n. 4, p. 4-11, 2003 b. 
Transitions in thought and practice: links, divergences and contradictions in post-critical inquiry. Environmental Education Research, Austrália: Alan Reid - Monash University, v. 11, n. 4, p. 391-400, sept. 2005.

Josgrilberg, Fabio Botelho. Cotidiano e invenção: os espaços de Michel de Certeau. São Paulo: Escrituras Editora, 2005.

Maffesoli, Michel. A violência totalitária: ensaio da antropologia política. Porto Alegre: Sulina, 2001.

. Elogio da razão sensível. 3. ed. Petropólis: Vozes, 2005.

Maturana, Humberto. Emoções e linguagem na educação e na política. Belo Horizonte: Editora UFMG, 1998.

. A ontologia da realidade. Belo Horizonte: Editora UFMG, 1997.

Morin, Edgar. Ciência com consciência. 12. ed. Rio de Janeiro: Bertrand Russel, 2008.

Peixoto, Elane; Golobovante, Maria da Conceição. Comunicação e espaço urbano: entrevista com o antropólogo Marc Augé. Revista da Associação Nacional dos Programas de Pós-Graduação em Comunicação, Brasília: Associação Nacional dos Programas de Pós-Graduação em Comunicação, v.11, n.1, p. 1-12, jan./abr. 2008.

Polkinghorne, Donald E. Narrative configuration in qualitative analysis. International Journal of Qualitative Studies in Education, Indianapolis: James Joseph Scheurich, School of Education, Indiana University-Purdue, v. 8, n. 1, p. 5-23, 1995.

TRISTÃo, Martha. Educação ambiental na formação de professores: redes de saberes. São Paulo; Annablume; Vitória: FACITEC, 2004.

A educação ambiental e o paradigma da sustentabilidade em tempos de globalização. In: Guerra, Antonio Fernando Silveira; Figueiredo, Mara Lúcia (Orgs.). Sustentabilidades em diálogos. Itajaí: Universidade do Vale do Itajaí, 2010. p. 157-169.

Tristão, Martha; Carvalho, Luiz Marcelo de. Grupos de pesquisa e GT22: Educação ambiental na Associação Nacional de Pós-Graduação e Pesquisa em Educação (ANPEd): uma síntese interpretativa. Ambiente E̋ Educação: Revista de Educação Ambiental, Rio Grande: Universidade Federal do Rio Grande, v. 14, n. 2, p. 87-92, 2009.

Veiga-Neto, Alfredo. Foucault e a educação. 2. ed. Belo Horizonte: Autêntica, 2007.

\section{SOBRE A AUTORA}

Martha Tristão é doutora em educação pela Universidade de São Paulo (USP). Professora da Universidade Federal do Espírito Santo (UFES).

E-mail: marthatristao@terra.com.br

Recebido em novembro de 2011 Aprovado em março de 2012 


\section{MARTHA TRISTÃO}

\section{Uma abordagem filosófica da pesquisa em educação ambiental}

Este artigo tem a intenção de associar o pensamento filosófico ambiental ou os princípios de uma ecofilosofia à pesquisa narrativa em educação ambiental, considerando o seu impacto na ciência, na vida e no desenvolvimento de sociedades sustentáveis. A abordagem metodológica defendida passa por uma investigação filosófica. O pensamento ecológico, como paradigma espistemológico, preconiza princípios metodológicos em que a abordagem da natureza envolve valores humanos e não se reduz ao aspecto científico apenas. Tal entendimento reconhece a existência de uma razão sensível como integrante da natureza humana, seus efeitos sociais e impactos ambientais. As bases ontológicas e epistemológicas que guiam pressupostos metodológicos e informam métodos e ações podem potencializar e enriquecer a área da educação ambiental. Busca ainda estabelecer um movimento congruente de metodologias de pesquisa com epistemologias e ontologias, questionar a natureza e os usos que são feitos da interpretação da educação ambiental.

Palavras-chave: processos de identificação; narrativas; culturas.

\section{A philosophical approach to research on environmental education}

This article aims at associating the environmental philosophical thought or the principles of an ecophilosophy with a narrative study about environmental education, considering its impact on science, life and the development of sustainable societies. The methodological approach advocated includes a philosophical investigation. As an epistemological paradigm, the ecological thinking advocates methodological principles in which environmental issues involve human values and are not limited to scientific aspects. It recognizes the existence of a sensible reason as part of human nature, and its social effects and environmental impacts as well. The ontological and epistemological bases that guide the methodological assumptions and inform methods and actions can enhance and enrich the environmental education field. It seeks to establish a consistent movement of research methodologies, epistemologies and ontologies, and also question the nature and the uses of the interpretation of environmental education.

Keywords: processes of identification; narratives; cultures.

\section{Un abordaje filosófico de la investigación en educación ambiental}

Este artículo tiene la intención de vincular el pensamiento filosófico ambiental, o los principios de una ecofilosofía, a la investigación narrativa en educación ambiental, teniendo en cuenta su impacto en la ciencia, la vida y el desarrollo de sociedades sostenibles. El enfoque metodológico propuesto incluye una investigación filosófica. El pensamiento ecológico, como paradigma epistemológico, preconiza principios metodológicos en los que el abordaje de la 
naturaleza envuelve valores humanos y no se reduce a su aspecto cientifico. Reconoce la existencia de una razón sensible como parte integrante de la naturaleza humana, sus impactos sociales y ambientales. Las bases ontológicas y epistemológicas que orientan presupuestos metodológicos e informan métodos y acciones pueden potenciar y enriquecer el campo de la educación ambiental. Establecer un movimiento congruente de metodologias de investigación con epistemologias y ontologias, cuestionar la naturaleza y los usos que se hacen de la interpretación de la educación ambiental.

Palabras clave: procesos de identificación; narrativas; culturas. 